\title{
Propofol protects against the neurotoxicity of 1-methyl-4-phenylpyridinium
}

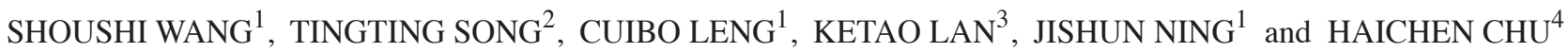 \\ Departments of ${ }^{1}$ Anesthesiology, ${ }^{2}$ Oncology and ${ }^{3}$ Cardiology, Qingdao Central Hospital, Qingdao, Shandong 266042; \\ ${ }^{4}$ Department of Anesthesiology, Affiliated Hospital of Qingdao University Medical College, \\ Qingdao, Shandong 266003, P.R. China
}

Received October 28, 2014; Accepted September 22, 2015

DOI: $10.3892 / \mathrm{mmr} .2015 .4570$

\begin{abstract}
Parkinson's disease (PD) is a progressive and degenerative disorder of the central nervous system, characterized by the loss of dopaminergic neurons and muscular rigidity. Treatment with propofol (2,6-diisopropylphenol) has been observed to attenuate oxidative stress injury via inhibition of programmed cell death. Results from the present study indicate that propofol treatment attenuates 1-methyl-4-phenylpyridinium $\left(\mathrm{MPP}^{+}\right)$-induced oxidative stress, which was demonstrated by increased levels of reactive oxygen species, 4-hydroxy-2-nonenal and protein carbonyls. Furthermore, it was demonstrated that propofol may ameliorate $\mathrm{MPP}^{+}$-induced mitochondrial dysfunction by increasing the level of ATP and the mitochondrial membrane potential. MTT and lactate dehydrogenase assays indicated that propofol treatment reduces cell vulnerability to $\mathrm{MPP}^{+}$-induced insult. Propofol was also observed to prevent apoptotic signals by reducing the ratio of Bcl-2-associated X protein to B-cell lymphoma 2, reducing the expression level of cleaved caspase- 3 and attenuating cytochrome $c$ release. Thus, propofol may present as a novel therapeutic strategy for the treatment of PD.
\end{abstract}

\section{Introduction}

Parkinson's disease (PD), the second most common neurodegenerative disease in the world, is characterized by the loss of dopaminergic neurons and muscular rigidity (1). A major product of the oxidation of 1-methyl-4-phenyl-1,2,3,6-tetrahydropyridine (MPTP) is 1-methyl-4-phenylpyridinium $\left(\mathrm{MPP}^{+}\right)$, which has been extensively used in a variety of in vitro systems to model PD (2). $\mathrm{MPP}^{+}$has been reported to be actively transported into dopaminergic neurons via the plasma membrane in

Correspondence to: Dr Shoushi Wang, Department of Anesthesiology, Qingdao Central Hospital, 127 Si Liu South Road, Qingdao, Shandong 266042, P.R. China

E-mail: wangss6806@yeah.net

Key words: propofol, 1-methyl-4-phenylpyridinium, oxidative stress, Parkinson's disease a similar manner to dopamine transporters (3). Neurotoxicity of $\mathrm{MPTP} / \mathrm{MPP}^{+}$is complex, and the overproduction of nitric oxide (NO), hydroxyl radical generation and apoptosis have all been associated with the neurotoxicity of $\mathrm{MPP}^{+}$(4). Furthermore, $\mathrm{MPP}^{+}$was reported to induce mitochondrial dysfunction by inhibiting the activity of complex I (5). However, the intracellular mechanisms of $\mathrm{MPP}^{+}$-induced neurotoxicity underlying the degenerative process require further elucidation.

Propofol (2,6-diisopropylphenol) is an intravenous anesthetic agent that has been widely administered as a short-acting intravenous anesthetic since the late 1980s (6). In addition to its application for maintenance of sedative effects as an anesthetic, various characteristics of propofol have been investigated in recent years. Notably, propofol demonstrates anti-oxidative (7) and anti-inflammatory properties (8). Propofol is chemically similar to the endogenous antioxidant, $\alpha$-tocopherol (vitamin E), therefore should theoretically demonstrate similar properties (9). Increasing evidence has indicated that propofol scavenges oxygen free radicals, and inhibits oxidative damage and the release of inflammatory factors (10). Notably, a previous study demonstrated the neuroprotective effects of propofol against amyloid $\beta(A \beta)$ toxicity in Alzheimer's disease (AD). In addition, propofol has been shown to protect the brain from ischemia-reperfusion injury (11). However, to the best of our knowledge, it is unknown whether propofol has similar protective effects on the pathophysiological changes in PD. Therefore, in the present study, the effect of propofol in reducing $\mathrm{MPP}^{+}$-induced toxicity was investigated in human SH-SY5Y cells.

\section{Materials and methods}

Cell culture, treatment and transfection. SH-SY5Y human neuroblastoma cells (American Type Culture Collection, Manassas, VA, USA) were cultured in Eagle's minimum essential medium (American Type Culture Collection) and Ham's F12 medium (American Type Culture Collection) containing $10 \%$ fetal bovine serum (FBS; Sigma-Aldrich, St. Louis, MO, USA) and $1 \%$ penicillin $(100 \mathrm{U} / \mathrm{ml})$ and streptomycin $(100 \mu \mathrm{g} / \mathrm{ml}$; Lonza, Walkersville, MD, USA). Cells were exposed to $50 \mu \mathrm{M} \mathrm{MPP}^{+}$(Sigma-Aldrich) in the presence or absence of 25 or $50 \mu \mathrm{M}$ propofol (Sigma-Aldrich) for $24 \mathrm{~h}$. 
Western blot analysis. Proteins were extracted from cultured cells using cell lysis buffer (Cell Signaling Technology, Inc., Danvers, MA, USA). Protein concentration was determined using a bicinchoninic acid protein assay kit (Sigma-Aldrich). The soluble protein solutions were mixed with $4 \mathrm{X}$ sample buffer (0.25 M Tris-HCl, 20\% mercaptoethanol, 8\% SDS, $20 \%$ sucrose, $0.008 \%$ bromophenol blue; $\mathrm{pH} 6.8$ ) and boiled for $5 \mathrm{~min}$. Equal quantities of protein $(20 \mu \mathrm{g})$ were loaded onto SDS-PAGE (10\% separation gel and 5\% spacer gel). The separation gel was then run at $80 \mathrm{~V}$ for $15 \mathrm{~min}$ and the spacer gel was run at $120 \mathrm{~V}$ for $1 \mathrm{~h}$ with $1 \mathrm{X}$ running buffer (25 mM Tris-HCl, 200 mM glycine, 0.1\% (w/v) SDS; Bio-Rad, Hercules, CA, USA). The gel was then transferred onto a polyvinylidene fluoride membrane (Bio-Rad Laboratories, Inc., Hercules, CA, USA) using a transfer buffer ( $25 \mathrm{mM}$ Tris, $192 \mathrm{mM}$ glycine and $20 \%$ methanol) at $80 \mathrm{~V}$ for $3 \mathrm{~h}$ in an ice-cold environment. Following blocking in 5\% skimmed milk in Tris-buffered saline with Tween-20 (TBST; $20 \mathrm{mM}$ Tris- $\mathrm{HCl}, 150 \mathrm{mM}$ sodium chloride, $0.1 \%$ Tween-20), the membranes were incubated with the following primary antibodies at $4^{\circ} \mathrm{C}$ overnight: Mouse monoclonal anti-human B cell lymphoma 2 (Bcl-2; 1:2,000; cat. no. sc-7382; Santa Cruz Biotechnology, Inc., Dallas, TX, USA); mouse monoclonal anti-human $\mathrm{Bcl}-2$-associated $\mathrm{X}$ protein (Bax; 1:3,000; cat. no. sc-20067; Santa Cruz Biotechnology, Inc.); mouse monoclonal anti-human cytochrome $c(1: 2,000$; cat. no. sc-514435; Santa Cruz Biotechnology, Inc.); mouse monoclonal anti-human cytochrome $c$ oxidase subunit IV isoform 1 (COX4; 1:5,000; cat. no. sc-376731; Santa Cruz Biotechnology, Inc.); rabbit polyclonal anti-human cleaved caspase-3 (1:1,000; cat. no. sc-22171-R; Santa Cruz Biotechnology, Inc.); mouse monoclonal anti-human $\beta$-actin (1:10,000; cat. no. sc-130065; Santa Cruz Biotechnology, Inc.). The membranes were subsequently incubated with horseradish peroxidase (HRP)-conjugated goat anti-mouse $\operatorname{IgG}(1: 5,000$; cat. no. sc-2005; Santa Cruz Biotechnology, Inc.) or HRP-conjugated goat anti-rabbit $\operatorname{IgG}(1: 5,000$; cat. no. sc-2004; Santa Cruz Biotechnology, Inc.) secondary antibodies for $1 \mathrm{~h}$ at room temperature. The membranes were washed three times with TBST and the proteins were detected with the enhanced chemiluminescence system (Thermo Fisher Scientific, Inc., Waltham, MA, USA). The relative densities of protein bands were analyzed using Image J 2.1 software (National Institutes of Health, Bethesda, MA, USA).

Protein carbonyl assay. Cells were lysed with cell lysis buffer (Cell Signaling Technology, Inc.) and protein samples from cells were adsorbed to wells of an ELISA plate (Thermo Fisher Scientific, Inc.) and reacted with 2,4-dinitrophenylhydrazine (DNPH; Sigma-Aldrich). The hydrazone adducts were incubated with an anti-DNPH antibody (1:1,000; Sigma-Aldrich; cat. no. HPA029675) for $1 \mathrm{~h}$ at $37^{\circ} \mathrm{C}$, and a secondary rat anti-mouse monoclonal antibody conjugated with HRP (1:3,000; Thermo Fisher Scientific, Inc.; cat. no. 04-6120) for $1 \mathrm{~h}$ at $37^{\circ} \mathrm{C}$. The method was calibrated using oxidized bovine serum albumin (BSA; Sigma-Aldrich), and prepared as previously described (12).

Reactive oxygen species (ROS) determination. Fluorescent dye, 2',7'-dichlorofluorescein-diacetate (DCFH-DA;
Sigma-Aldrich) was used to measure the intracellular ROS level (13). Following the cell treatment with $50 \mu \mathrm{M} \mathrm{MPP}$ in the presence or absence of 25 or $50 \mu \mathrm{M}$ propofol for $24 \mathrm{~h}$, SH-SY5Y cells were loaded with $10 \mu \mathrm{M}$ DCFH-DA and incubated in a $\mathrm{CO}_{2}$ incubator for $30 \mathrm{~min}$ at $37^{\circ} \mathrm{C}$. The cells were washed with phosphate buffered saline (PBS) three times, and fluorescence signals were recorded using a fluorescence microscope (IX71SIF-2; Olympus Corporation, Tokyo, Japan).

4-Hydroxy-2-nonenal (4-HNE) immunofluorescence staining. Following the indicated treatment, the cells were fixed in $4 \%$ paraformaldehyde (Sigma-Aldrich) for $10 \mathrm{~min}$ at room temperature (RT) followed by permeabilization with $0.4 \%$ Triton X-100 (Sigma-Aldrich) on ice for $15 \mathrm{~min}$. Cells were blocked with $5 \%$ BSA and 2.5\% FBS in PBS with Tween-20 (Sigma-Aldrich). Subsequently, cells were incubated with anti-4-HNE (Cell Signaling Technology, Inc.) for $2 \mathrm{~h}$ at RT followed by incubation with Invitrogen Alexa-594-conjugated secondary antibodies (Thermo Fisher Scientific) for $1 \mathrm{~h}$ at RT. Staining signals were recorded using a fluorescence microscope.

Statistical analysis. Results are presented as the mean \pm standard error of the mean of at least three experiments. Results obtained from different experiments were analyzed using one-way analysis of variance and $\mathrm{P}<0.05$ was considered to indicate a statistically significant difference.

Cell viability determination. An MTT (Sigma-Aldrich) reduction assay was used to determine cell viability incubated at $37^{\circ} \mathrm{C}$ at 5,000 per well. The cells were cultured in 96-well plates and exposed to $50 \mu \mathrm{M} \mathrm{MPP}{ }^{+}$in the presence or absence of 25 or $50 \mu \mathrm{M}$ propofol for $24 \mathrm{~h}$. MTT (at a final concentration of $1.0 \mathrm{mg} / \mathrm{ml}$ ) was then added to each well and incubated for $2 \mathrm{~h}$ at $37^{\circ} \mathrm{C}$ in the dark. The formed formazane crystal was dissolved in dimethyl sulfoxide (Sigma-Aldrich). The solution was agitated at room temperature for $10 \mathrm{~min}$, and absorbance was determined at $570 \mathrm{~nm}$ using a iMark Microplate Absorbance Reader (Bio-Rad Laboratories) to index cell viability.

Determination of lactate dehydrogenase $(\mathrm{LDH})$ release. Cells were cultured in 96-well plates and exposed to $50 \mu \mathrm{M} \mathrm{MPP}^{+}$ in the presence or absence of 25 or $50 \mu \mathrm{M}$ propofol for $24 \mathrm{~h}$. A Cytotoxicity Detection kit (Sigma-Aldrich) was used to determine the levels of LDH released from the damaged cells, according to the manufacturer's instructions. Absorbance was determined at $490 \mathrm{~nm}$ using a microplate reader to quantify the levels of $\mathrm{LDH}$.

Intracellular NO determination. The cells were exposed to $50 \mu \mathrm{M} \mathrm{MPP}^{+}$in the presence or absence of 25 or $50 \mu \mathrm{M}$ propofol for $24 \mathrm{~h}$. The levels of intracellular NO was then determined suing a diaminofluorescein-FM diacetate (DAF-FM DA) cell-permeable fluorescent probe (Sigma-Aldrich). Briefly, $10 \mu \mathrm{M}$ DAF-FM DA was loaded and incubated at $37^{\circ} \mathrm{C}$ for $30 \mathrm{~min}$ in the dark. Fluorescence signals were captured using a a IX71SIF-2 fluorescence microscope.

Mitochondrial membrane potential (MMP) determination. Cells were exposed to $50 \mu \mathrm{M} \mathrm{MPP}^{+}$in the presence or absence 
A
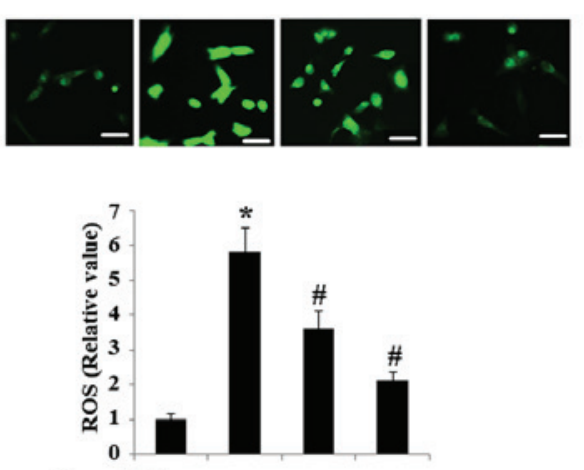

Propofol $0 \quad 0 \quad 25 \mu \mathrm{M} \quad 50 \mu \mathrm{M}$

MPP+ $\quad 0 \quad 50 \mu \mathrm{M} 50 \mu \mathrm{M} 50 \mu \mathrm{M}$
B

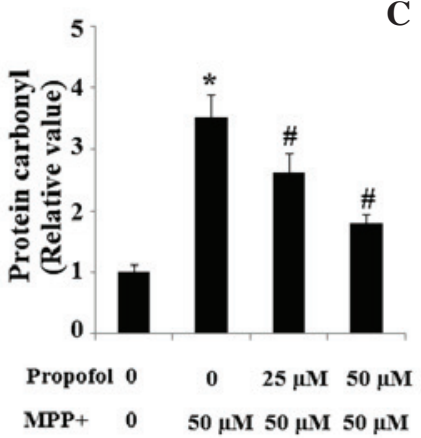

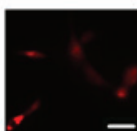
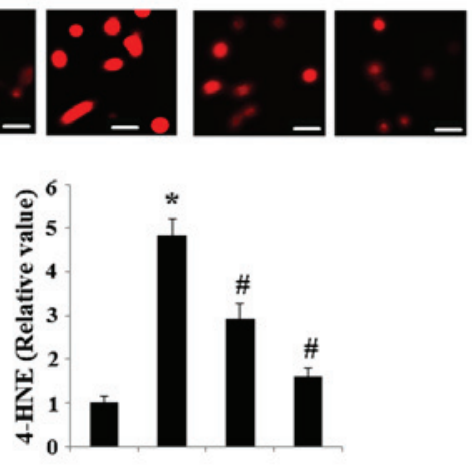

Propofol $0 \quad 0 \quad 25 \mu \mathrm{M} 50 \mu \mathrm{M}$

MPP+ $\quad 0 \quad 50 \mu \mathrm{M} 50 \mu \mathrm{M} 50 \mu \mathrm{M}$

Figure 1. Protective effects of propofol against oxidative stress in SH-SY5Y cells. (A) ROS level was measured by 2',7'-dichlorofluorescein-diacetate. Representative fluorescence images of intracellular ROS and quantitative analysis demonstrated increased intracellular ROS accumulation in cells exposed to $\mathrm{MPP}^{+}$, which was inhibited by propofol in a dose-dependent manner. Four images represent the various doses of propofol. (B) Protein carbonyl was measured by ELISA. Quantitation demonstrated increased protein carbonyl accumulation in cells exposed to $\mathrm{MPP}^{+}$, which was inhibited by propofol in a dose-dependent manner. (C) Representative fluorescence images of intracellular 4-HNE and quantitative analysis demonstrated increased intracellular 4-HNE accumulation in cells exposed to $\mathrm{MPP}^{+}$, which was inhibited by propofol in a dose-dependent manner. Analysis of variance: " $\mathrm{P}<0.001 \mathrm{vs}$. control; ${ }^{*} \mathrm{P}<0.001$ vs. cells exposed to $\mathrm{MPP}^{+}$. ROS, reactive oxygen species; 4-HNE, 4-hydroxy-2-nonenal; $\mathrm{MPP}^{+}$, 1-methyl-4-phenylpyridinium. Error bars represent the standard deviation.
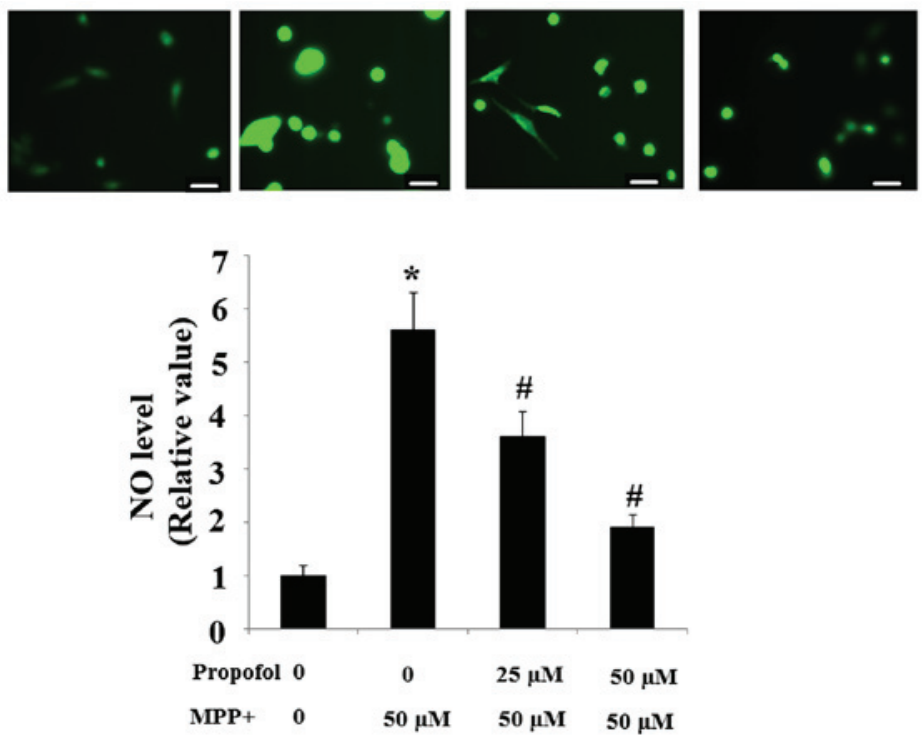

Figure 2. Protective effects of propofol on NO production in SH-SY5Y cells. NO was measured by 4,5-diaminofluorescein-diacetate assay. Analysis of variance: ${ }^{*} \mathrm{P}<0.001$ vs. control; ${ }^{\#} \mathrm{P}<0.001$ vs. cells exposed to $\mathrm{MPP}^{+}$. NO, nitric oxide; $\mathrm{MPP}^{+}, 1$-methyl-4-phenylpyridinium. Error bars represent the standard deviation.
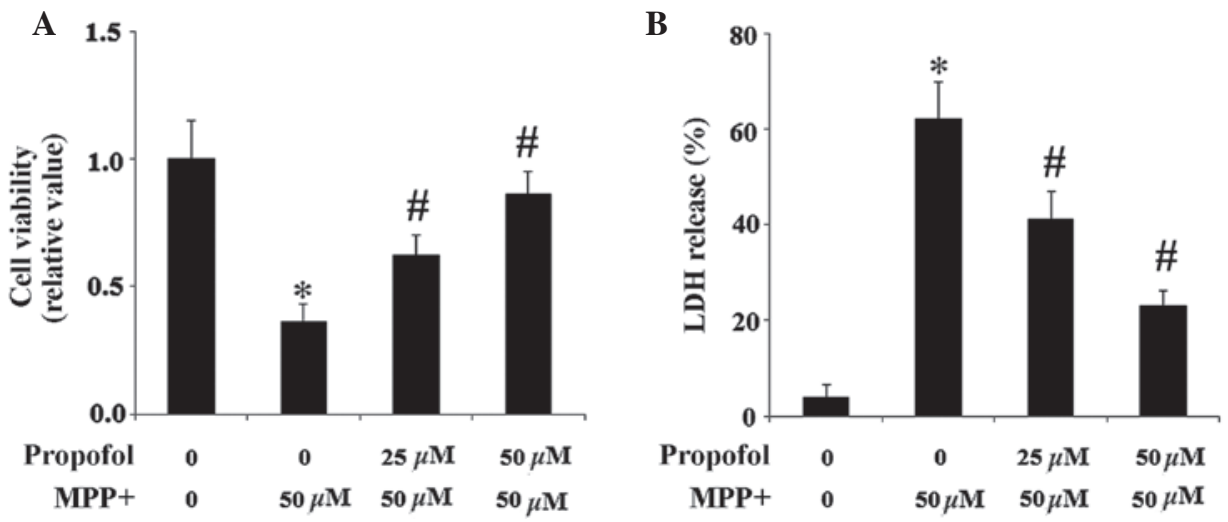

Figure 3. Effects of propofol on cell viability and LDH release in SH-SY5Y cells following incubation with MPP. (A) Cell viability was determined by the MTT assay; (B) LDH release was determined using a commercial kit. Analysis of variance: ${ }^{*} \mathrm{P}<0.001$ vs. control; ${ }^{*} \mathrm{P}<0.001$ vs. the cells exposed to MPP ${ }^{+}$. MPP , 1-methyl-4-phenylpyridinium; LDH, lactate dehydrogenase. Error bars represent the standard deviation. 
A
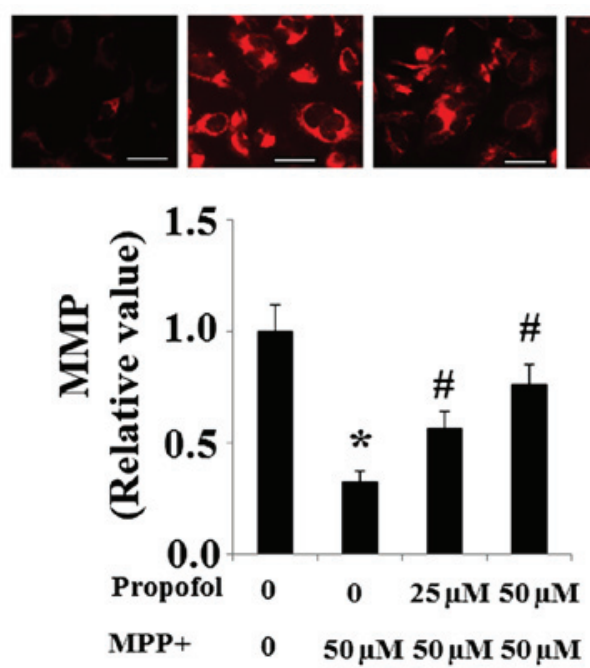

B

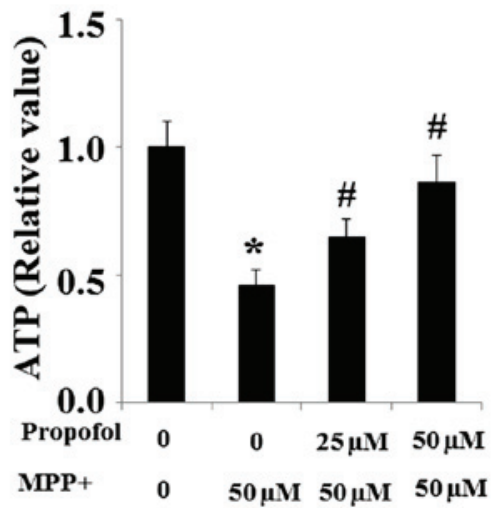

Figure 4. Effect of propofol on mitochondrial function in MPP+-treated SH-SY5Y cells. (A) Cell viability was determined by the fluorescence dye tetramethylrhodamine methyl ester (B) ATP levels were determined using a commercial kit. Analysis of variance: "P $<0.001$ vs. control; ${ }^{*} \mathrm{P}<0.001$ vs. cells exposed to $\mathrm{MPP}^{+}$. MPP+ , 1-methyl-4-phenylpyridinium. Error bars represent the standard deviation.

A

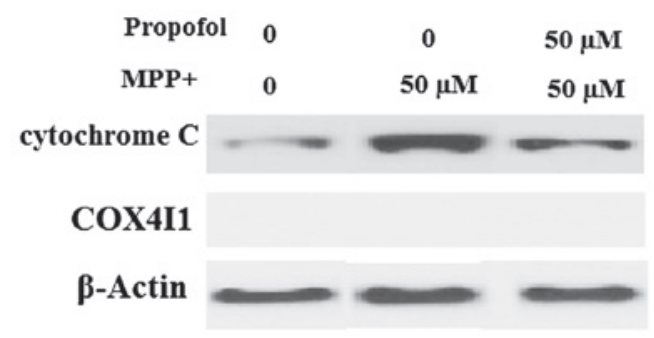

Figure 6. Immunoblots for cytochrome $c$ in cytosolic fractions demonstrating that propofol reduces the release of cytochrome $c$. COX-4 served as a control for the fraction efficiency. $\mathrm{MMP}^{+}$, 1-methyl-4-phenylpyridinium, COX-4, cytochrome $c$ oxidase subunit IV isoform 1.

of 25 or $50 \mu \mathrm{M}$ propofol for $24 \mathrm{~h}$. The MMP was then determined using a tetramethylrhodamine methyl ester (TMRM) fluorescence dye (Thermo Fisher Scientific, Inc.) according to the manufacturer's protocol. Briefly, the cells were treated with $20 \mathrm{nmol} / 1 \mathrm{TMRM}$ and incubated for $60 \mathrm{~min}$ at room temperature. Following three washes in PBS, fluorescence signals were captured using a IX71SIF-2 fluorescence microscope. $\mathrm{X}$ protein. Error bars represent the standard deviation.

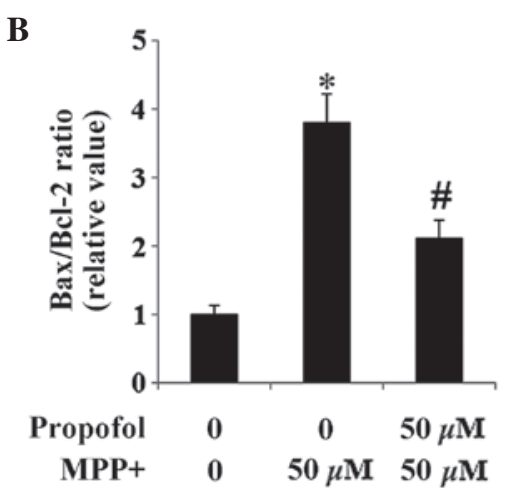

Figure 5. Effects of propofol on the expression of Bax and Bcl-2 in SH-SY5Y cells exposed to MPP . (A) Representative images of immunoblots for Bax and Bcl-2. $\beta$-actin served as a loading control. (B) Quantitative analysis of the ratio of Bax and Bcl-2. All experiments were repeated three times. Analysis of variance: ${ }^{\mathrm{P}}<0.001$ vs. control; ${ }^{\mathrm{P}} \mathrm{P}<0.001$ vs. cells exposed to $\mathrm{MPP}^{+}$. $\mathrm{MMP}^{+}$, 1-methyl-4-phenylpyridinium; BCL-2, B-cell lymphoma 2; Bax, BCL2-associated

\begin{tabular}{c|ccc}
$\begin{array}{c}\text { Propofol } \\
\text { MPP+ }\end{array}$ & 0 & 0 & $\mathbf{5 0} \mu \mathbf{M}$ \\
$\begin{array}{c}\text { Cleaved } \\
\text { caspase-3 }\end{array}$ & & $50 \mu \mathrm{M}$ & $\mathbf{5 0} \mu \mathbf{M}$ \\
& & & \\
$\beta$-actin & & \\
\hline
\end{tabular}

Figure 7. Immunoblots of cleaved caspase-3 expression demonstrating the effects of propofol on the expression level of cleaved caspase- 3 in $\mathrm{SH}-\mathrm{SY} 5 \mathrm{Y}$ cells exposed to $\mathrm{MPP}^{+}$. $\beta$-actin served as a loading control. $\mathrm{MMP}^{+}$, 1-methyl-4-phenylpyridinium.

Determination of ATP levels using a bioluminescence assay. The cells were treated with $50 \mu \mathrm{M} \mathrm{MPP}^{+}$in the presence or absence of 25 or $50 \mu \mathrm{M}$ propofol for $24 \mathrm{~h}$. The levels of ATP were determined using an ATP bioluminescence assay kit (Roche Diagnositics, Basel, Switzerland) according to the manufacturer's instructions. Briefly, the cells were lysed and centrifuged at $10,000 \mathrm{x} \mathrm{g}$ for $10 \mathrm{~min}$ at $4^{\circ} \mathrm{C}$. The supernatants 
were then collected and mixed with equal amount of luciferase reagent (Promega Corporation, Madison, WI, USA), which catalyzed light production from ATP and luciferin. The signals were recorded using a microplate luminometer (GloMax 96 Microplate Luminometer; Promega Corporation) and used to index ATP concentration.

\section{Results}

Propofol attenuates $\mathrm{MPP}^{+}$-induced oxidative stress. The production of intracellular ROS in SH-SY5Y cells was assessed using the fluorescence probe, DCFH-DA. The results in the present study indicate that the intracellular ROS level in cells exposed to $\mathrm{MPP}^{+}$is significantly higher when compared with the controls, which was reduced by propofol treatment in a dose-dependent manner (Fig. 1A). Consistent with these results, the basal level of protein carbonyl (Fig. 1B) and 4-HNE (Fig. 1C) was increased by exposure to $\mathrm{MPP}^{+}$, and these increases were prevented by pretreatment with propofol.

Propofol ameliorates the generation of $\mathrm{NO}$ induced by $\mathrm{MPP}^{+}$. Intracellular production of NO is the main component of reactive nitrogen species (RNS). The intracellular NO level in SH-SY5Y cells exposed to $\mathrm{MPP}^{+}$cells was observed to be significantly higher than in control cells; however, increases in the NO level were suppressed in a dose-dependent manner by pretreatment with propofol (Fig. 2).

Propofol inhibits MPP ${ }^{+}$-induced cell death. The MTT reduction assay was used to determine cell viability. As presented in Fig. 3A, propofol treatment ameliorated the impaired cell viability induced by $50 \mu \mathrm{M} \mathrm{MPP}^{+}$exposure. To further demonstrate that propofol increased cell resistance to $\mathrm{MPP}^{+}$, the levels of cellular toxicity were determined using a LDH assay. Pretreatment with propofol in SH-SY5Y cells mitigated $\mathrm{MPP}^{+}$-induced $\mathrm{LDH}$ release following a 24-h incubation (Fig. 3B).

Propofol rescues $\mathrm{MPP}^{+}$-induced mitochondrial dysfunction. The levels of MMP were investigated to determine mitochondrial function. Significantly reduced MMP in SH-SY5Y cells was observed following $\mathrm{MPP}^{+}$exposure, which was partially restored by pretreatment with propofol (Fig. 4A). Decreased levels of ATP demonstrate mitochondrial dysfunction and results from the present study indicate that the level of ATP was significantly reduced in SH-SY5Y cells exposed to $\mathrm{MPP}^{+}$ when compared with the non-treated controls. However, the decreased production of ATP was partially ameliorated by propofol treatment (Fig. 4B).

Propofol reverses the alteration of Bax and Bcl-2 induced by $M P P^{+}$. The difference between the effect of propofol on the pro- and anti-apoptotic pathways in SH-SY5Y cells was examined. The Bcl-2 family members are essential in the mitochondrial pathway of apoptosis (14). It has been previously reported that Bax is significantly upregulated and Bcl-2 is downregulated in $\mathrm{MPP}^{+}$-induced neurotoxicity (15). Results from the current study indicate that SH-SY5Y cells exhibit an increase in the expression levels of Bax and a marked decrease in the expression levels of $\mathrm{Bcl}-2$ following $\mathrm{MPP}^{+}$exposure.
Furthermore, these expression levels were restored by administration of propofol (Fig. 5).

Propofol suppresses the release of cytochrome c and caspase-3 cleavage. Impaired MMP results in the release of cytochrome $c$ into the cytoplasm, followed by activation of caspase-3. Therefore, the effects of propofol on cytochrome $c$ release were investigated. As presented in Fig. 6, cytochrome $c$ levels in the cytosol were significantly increased in cells following $\mathrm{MPP}^{+}$exposure, which was markedly prevented by propofol treatment. COX4 served as the internal control for cytosolic fractions. Notably, it was observed that caspase-3 expression levels were increased in SH-SY5Y cells following $\mathrm{MPP}^{+}$exposure; however, the increased expression was significantly attenuated by treatment with propofol (Fig. 7).

\section{Discussion}

PD has the second highest incidence of the progressive degenerative central nervous system disorders. PD is characterized by the loss of dopaminergic neurons and muscular rigidity (16). The causes and underlying mechanisms of $\mathrm{PD}$ are complex and remain to be elucidated, however, free radicals produced during oxidative stress contribute to the mechanism of cell death in PD. Antioxidant and anti-apoptosis therapeutic strategies have become attractive adjunct methods for PD treatment (17). $\mathrm{MPP}^{+}$has been widely demonstrated to result in hydroxyl radical generation (4), mitochondrial dysfunction (18), and apoptosis (19) in in vitro PD studies. In the present study, the effects of propofol on the neurotoxicity of PD-associated $\mathrm{MPP}^{+}$were investigated. Patterns of oxidative stress, mitochondrial dysfunction and cell susceptibility were analyzed. Data from the present study demonstrates that $\mathrm{MPP}^{+}$-induced oxidative stress, mitochondrial dysfunction and apoptosis may be rescued by treatment with propofol.

Propofol is widely adopted for clinical studies as an intravenous general anesthetic (20). It is administered in anesthesia and sedation, as it is fast acting and patients rapidly regain full consciousness, as the agent does not accumulate over time with continuous infusion (21). Notably, increasing evidence has demonstrated the anti-inflammatory properties of propofol (8). Corcoran et al (22) reported that propofol may reduce neutrophil adhesion to vascular endothelial cells by inhibiting the expression of adhesion molecule, P-selectin. A previous study demonstrated that propofol may inhibit oxidative damage by scavenging oxygen free radicals, which is consistent with the findings of the present study that propofol may possess an anti-oxidative stress property against $\mathrm{MPP}^{+}$.

Notably, as an important neurotoxin, $\mathrm{MPP}^{+}$induces apoptotic activity in dopaminergic neurons. In the present study, apoptosis induced by $\mathrm{MPP}^{+}$is partially restored by propofol treatment. Propofol was also demonstrated to decrease the expression of Bax and increase the expression of $\mathrm{Bcl}-2$ in $\mathrm{SH}-\mathrm{SY} 5 \mathrm{Y}$ cells exposed to $\mathrm{MPP}^{+}$. This may explain the results in the present study that propofol treatment also inhibited cytochrome $c$ release and caspase- 3 activation. The results indicate that propofol protected the SH-SY5Y cells against $\mathrm{MPP}^{+}$-induced apoptosis via the inhibition of the mitochondrial apoptosis pathway. In addition, propofol has 
been demonstrated to inhibit cardiomyocyte apoptosis and the release of inflammatory factors (10).

Previous studies have reported the neuroprotective effects of propofol in neurological disorders. For example, a previous study demonstrated that propofol treatment may inhibit AD pathogenesis. The apoptosis rate was significantly decreased when cells were administered with $A \beta_{25-35}$ and propofol, and an increase in Bcl-2 expression and a decrease in tau phosphorylation were also observed, when compared with $\mathrm{A} \beta_{25-35}$ treatment alone (23). In addition, previous studies have suggested that propofol may exert neuroprotective effects, particularly in ischemia-reperfusion injury conditions, including hypoxemia and hypothermia (11). In conclusion, the results of the present study demonstrate that propofol is a potential therapeutic agent for the treatment of PD. Further investigation may elucidate the underlying mechanisms of PD, as well as those of additional neurodegenerative diseases.

\section{References}

1. Dauer W and Przedborski S: Parkinson's disease: Mechanisms and models. Neuron 39: 889-909, 2003.

2. Chiba K, Trevor AJ and Castagnoli N Jr: Active uptake of MPP ${ }^{+}$, a metabolite of MPTP, by brain synaptosomes. Biochem Biophys Res Commun. 128: 1228-1232, 1985.

3. Kopin IJ and Markey SP: MPTP toxicity: Implications for research in Parkinson's disease. Annu Rev Neurosci 11: 81-96, 1988.

4. Obata T: Nitric oxide and MPP+-induced hydroxyl radical generation. J Neural Transm 113: 1131-1144, 2006.

5. Dawson TM and Dawson VL: Molecular pathways of neurodegeneration in Parkinson's disease. Science 302: 819-822, 2003.

6. Saraghi M, Badner VM, Golden LR and Hersh EV: Propofol: An overview of its risks and benefits. Compend Contin Educ Dent 34: 252-258, 2013.

7. Yamaguchi S, Hamaguchi S, Mishio M, Okuda Y and Kitajima T: Propofol prevents lipid peroxidation following transient forebrain ischemia in gerbils. Can J Anaesth 47: 1025-1030, 2000.

8. Inada T, Kubo K and Shingu K: Possible link between cyclooxygenase-inhibiting and antitumor properties of propofol. J Anesth 25: 569-575, 2011.

9. Aarts L, van der Hee R, Dekker I, de Jong J, Langemeijer H and Bast A: The widely used anesthetic agent propofol can replace alpha-tocopherol as an antioxidant. FEBS Lett 357: $83-85,1995$
10. Li H, Tan J, Zou Z, Huang CG and Shi XY: Propofol post-conditioning protects against cardiomyocyte apoptosis in hypoxia/reoxygenation injury by suppressing nuclear factor-kappa B translocation via extracellular signal-regulated kinase mitogen-activated protein kinase pathway. Eur J Anaesthesiol 28: 525-534, 2011.

11. Harman F, Hasturk AE, Yaman M, Arca T, Kilinc K, Sargon MF and Kaptanoglu E: Neuroprotective effects of propofol, thiopental, etomidate, and midazolam in fetal rat brain in ischemia-reperfusion model. Childs Nerv Syst 28: 1055-1062, 2012.

12. Sheng B, Gong K, Niu Y, Liu L, Yan Y, Lu G, Zhang L, Hu M, Zhao N, Zhang $\mathrm{X}$, et al: Inhibition of $\gamma$-secretase activity reduces Abeta production, reduces oxidative stress, increases mitochondrial activity and leads to reduced vulnerability to apoptosis: implications for the treatment of Alzheimer's disease. Free Radic Biol Med 46: 1362-1375, 2009.

13. Sheng BY, Niu Y, Zhou H, Yan JX, Zhao NM, Zhang XF and Gong YD: The mitochondrial function was impaired in APP knockout mouse embryo fibroblast cells. Chin Sci Bull 54: 1725-1731, 2009.

14. Park JR and Hockenbery DM: BCL-2, a novel regulator of apoptosis. J Cell Biochem. 60: 12-17, 1996.

15. Zhou J, Sun Y, Zhao X, Deng Z and Pu X: 3-O-demethylswertipunicoside inhibits $\mathrm{MPP}^{+}$-induced oxidative stress and apoptosis in PC12 cells. Brain Res 1508: 53-62, 2013.

16. Crosiers D, Theuns J, Cras P and Van Broeckhoven C: Parkinson disease: Insights in clinical, genetic and pathological features of monogenic disease subtypes. J Chem Neuroanat 42: 131-141, 2011.

17. Moore DJ, West AB, Dawson VL and Dawson TM: Molecular pathophysiology of Parkinson's disease. Annu Rev Neurosci 28: 57-87, 2005.

18. Boada J, Cutillas B, Roig T, Bermúdez J and Ambrosio S: $\operatorname{MPP}(+)$-induced mitochondrial dysfunction is potentiated by dopamine. Biochem Biophys Res Commun. 268: 916-920, 2000.

19. Sheehan JP, Palmer PE, Helm GA and Tuttle JB. MPP' induced apoptotic cell death in SH-SY5Y neuroblastoma cells: An electron microscope study. J Neurosci Res 48: 226-237, 1997.

20. Kanto JH: Propofol, the newest induction agent of anesthesia. Int J Clin Pharmacol Ther Toxicol 26: 41-57, 1988.

21. McNeir DA, Mainous EG and Trieger N: Propofol as an intravenous agent in general anesthesia and conscious sedation. Anesth Prog 35: 147-151, 1988.

22. Corcoran TB, O'Shea A, Engel A and Shorten GD: The influence of propofol on P-selectin expression and nitric oxide production in re-oxygenated human umbilical vein endothelial cells. Acta Anaesthesiol Scand 50: 348-354, 2006.

23. Zhang R, Xu J, Liu YY, Zuo PP, Yang N, Ji C, Wang Y, Wang H, Wu AS and Yue Y: Propofol may protect PC12 cells from $\beta$-amyloid ${ }_{25-35}$ induced apoptosis through the GSK-3 $\beta$ signaling pathway. Chin Med J (Engl) 126: 1884-1889, 2013. 